\title{
Prevalence Difference of Cigarette Smoking in Different Iranian Citizens Based on Reliable Reported Studies
}

\author{
Forod Salehi, ${ }^{1}$ and Mohamad Mehdi Hassanzade Taheri ${ }^{2,}$ \\ ${ }^{1}$ Birjand Cardiovascular Diseases Research Center, Birjand University of Medical Sciences, Birjand, IR Iran \\ ${ }^{2}$ Department of Anatomy, Faculty of Medicine, Birjand University of Medical Sciences, Birjand, IR Iran \\ "Corresponding author: Mohammad Mehdi Hassanzadeh Taheri, Associated professor of Anatomical Sciences, Department of Anatomy, Faculty of Medicine, Birjand University \\ of Medical Sciences, Birjand, Iran. Tel: +98-5632381511, E-mail: mmhtahery35@gmail.com
}

Received 2016 June 05; Accepted 2016 July 16.

Keywords: Prevalence, Cigarette, Smoking

\section{Dear Editor}

We read in detail the interesting article by Ziaee et al focused on " the Prevalence of Cigarette Smoking and Related Factors in Birjand, Iran During Year 2014" which has been published in your Modern Care journal (1). According to importance of subject and special cultural conditions in east of our country the aim of this letter is to report about prevalence of cigarette smoking in different studies carried out in Birjand city in comparison with other provinces of Iran.

Smoking is a dangerous behavior that causes multiple problems in general health population and impose a heavy treatment budgeting to health service. In addition, smoking is an important risk factor for cardiac, pulmonary and cerebral diseases.Cigarette smoking is the most important reason of mortality in 35-69 years old population in developing countries. Based on the World health organization (WHO) report 25\% of adults in all of the world smoke cigarettes and tobaccos (2). Prevalence of cigarette smoking decreased from $38 \%$ to $24 \%$ in developed countries while this rate has increased to $76 \%$ in developing countries in 2009 (2).WHO reports show that smoking prevalence growth annually about $8 \%$ in eastern neighbors of Iran such as Afghanistan (3).

Also, prevalence of cigarette smoking was12 \% in Iran and 30\%, 23\%, 25\%, 20\% in Jordan, Pakistan, Qatar and Saudi Arabia, respectively in 2008 (4). Furthermore, a metaanalysis carried out in Iran, 2012, has reported the prevalence of cigarette smoking 19.8-21.7\% in men and 0.94-3.6\% in women and $13.9 \%$ in both genders. (4). In another metaanalysis study Moosazade et al. (2013) showed that rate of smoking increased based on aging from 12.3 to $38.4 \%$ and 0.6 to $9.8 \%$ in men and women, respectively (5) while in Ziaee et al. study prevalence of smoking was 7\% (12. $7 \%$ in men, $2 \%$ in women) (1). Moreover, Moosazade et al. study showed that prevalence of smoking rate in male to female was $6.02 \%$ that is similar to Ziaee et al. study.
The prevalence of smoking in different provinces of Iran is completely different (e.g. Mazandaran (Babol) 32.4\% and Hamadan 17.2\%) which are higher than southern Khorasan province (5).

Prevalence of smoking in neighbor provinces of Birjand such as Kerman, Sistan and Balochestan, KhorasanRazavi and Yazd are 7.3\%, 20.8\%, 12.7\% and 8.6\%, respectively (5) which are higher than the study of Ziaee et al. in Birjand. Another meta-analysis study showed that by aging up to 25 years-old prevalence of smoking increases steeply, then decreases after age of 45 years-old which is similar to Ziaee et al. study $(6,7)$. Mortazavi et al. study showed that prevalence of smoking among the students of Birjand universities was $31.5 \%$ in 2009 (8). Mehrpour et al. study showed that education level has a protective effect on smoking (8). Furthermore, this study showed that there is a significant relation between smoking with injective and non-injective drug abuse which is similar to ziaee et al. study (9). In conclusion, smoking prevalence which is reported in Ziaee et al. study is less than other reports probably due to the differences in method of study or in criteria of smoking, stigma of smoking due to negative vision in small societies or high education level in Birjand city.

\section{References}

1. Ziaee M, Hajihosseini M, Sharifzadeh G, Kazemi T, Azarkar G, Saljoughi M. Prevalence of Cigarette Smoking and Related Factors in Birjand, Iran During Year 2014. Modern Care J. 2016;13(2):9257. doi: 10.17795/modernc.9257.

2. Organization WH . WHO global report on trends in prevalence of tobacco smoking 2015. World Health Organization; 2015.

3. Platzer M, Mirella F. United Nations International Drug Control Programme responds. New West Indian Guide/Nieuwe West-Indische Gids. $2002 ; 76$ (1-2):89-93.

4. Organization WH . WHO Report on the Global Tobacco Epidemic. Geneva, Switzerland: World Health Organization, MPOWER package; 2008. 
5. Moosazadeh M, Ziaaddini H, Mirzazadeh A, Ashrafi-Asgarabad A, Haghdoost AA. Meta-analysis of smoking prevalence in Iran. Addiction and Health. 2013;5(3-4):140-53. [PubMed: 24494171].

6. HashemiH $\mathrm{H}$. The prevalence of cigarette smoking in residents of Tehran. Archives of Iranian medicine. Pneumonol Alergol Pol. 2009;12(4):358-64.

7. Boskabady MH, Mahmoudinia M, Eslamizade MJ, Boskabady M, Shakeri MT, Heydari GR. The prevalence of smoking among the population in the city of Mashhad (north east of Iran) and pulmonary function tests among smokers. Pneumonol Alergol Pol. 2011;79(1):21-5. [PubMed: 21190149].

8. Mortazavi Moghadam GR, Madarshahian F, Tabiei S, Pejmankhah S, Sadeghi M. Prevalence of drug abuse among the student of Birjand Universities (2003). Modern Care Journal. 2009;6(1):60-4.

9. Goodarzi F, Karrari P, Eizadi-Mood N, Mehrpour O, Misagh R, Setude S, et al. Epidemiology of drug abuse (chronic intoxication) and its related factors in a MMT Clinic in Shiraz, Southern Iran. Iranian Journal of Toxicology. 2011;4(4):377-80. doi: 10.1163/13822373-90002545. 